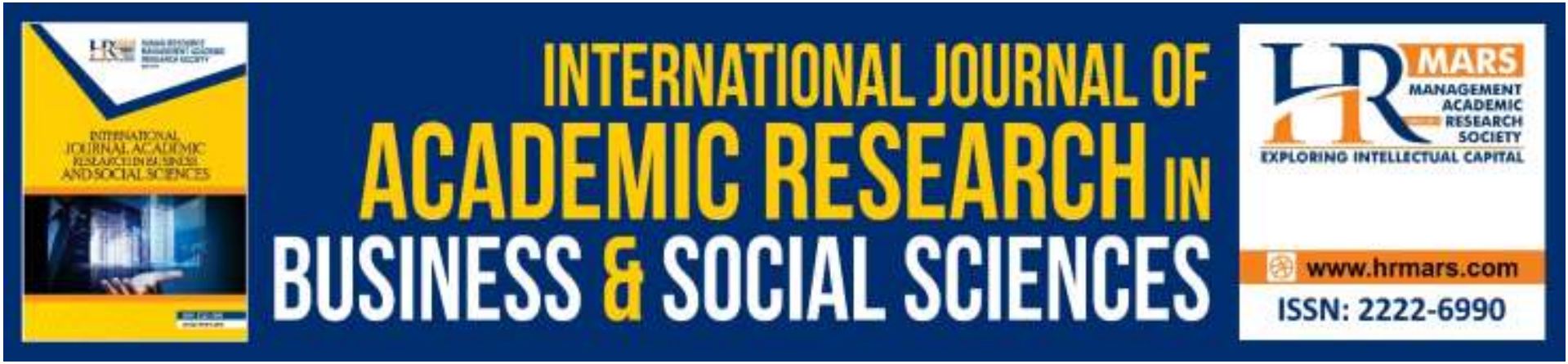

\title{
Applying the Theory of Planned Behavior to Healthy Eating Intention among Malaysian Adults
}

Ismawati Sharkawi, Malisah Latip and Zainal Abidin Mohamed

To Link this Article: http://dx.doi.org/10.6007/IJARBSS/v11-i17/11387 $\quad$ DOI:10.6007/IJARBSS/v11-i17/11387

Received: 05 August 2021, Revised: 27 August 2021, Accepted: 23 September 2021

Published Online: 08 October 2021

In-Text Citation: (Sharkawi et al., 2021)

To Cite this Article: Sharkawi, I., Latip, M., \& Mohamed, Z. A. (2021). Applying the Theory of Planned Behavior to Healthy Eating Intention among Malaysian Adults. International Journal of Academic Research in Business and Social Sciences, 11(17), 17-26.

Copyright: (C) 2021 The Author(s)

Published by Human Resource Management Academic Research Society (www.hrmars.com)

This article is published under the Creative Commons Attribution (CC BY 4.0) license. Anyone may reproduce, distribute, translate and create derivative works of this article (for both commercial and non-commercial purposes), subject to full attribution to the original publication and authors. The full terms of this license may be seen

at: http://creativecommons.org/licences/by/4.0/legalcode

Special Issue Title: Empowering Community and Beyond, iRandau, 2021, Pg. 17 - 26

http://hrmars.com/index.php/pages/detail/IJARBSS

JOURNAL HOMEPAGE

Full Terms \& Conditions of access and use can be found at http://hrmars.com/index.php/pages/detail/publication-ethics 


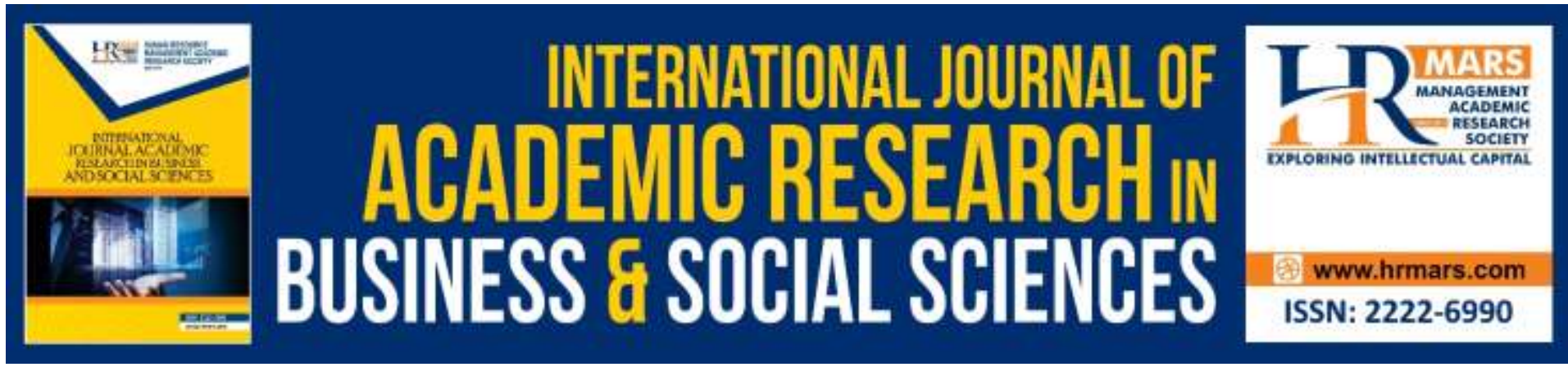

\title{
Applying the Theory of Planned Behavior to Healthy Eating Intention among Malaysian Adults
}

\author{
Ismawati Sharkawi ${ }^{1}$, Malisah Latip ${ }^{1}$ and Zainal Abidin \\ Mohamed $^{2}$ \\ ${ }^{1}$ Department of Social Science and Management, Faculty of Humanities, Management and \\ Science, Universiti Putra Malaysia Bintulu Campus, Sarawak, ²Department of Agribusiness \\ and Bioresource Economics, Faculty of Agriculture, Universiti Putra Malaysia. \\ Email: ismawat@upm.edu.my
}

\begin{abstract}
Despite the rising awareness on practicing healthy eating habits, statistics show the severity of the health state of Malaysian population. This indicates that most people may not have transformed their awareness into healthier eating behaviors. In response to this discrepancy between awareness and behavior, it is crucial to develop some basis for understanding the intention towards healthy eating as intention is believed to lead to performing desired behaviors. Therefore, this study aimed to identify the significant factors influencing Malaysians' healthy eating intention with the application of Theory of Planned Behavior (TPB). A sample of 1,719 adults participated in this study. The data were analyzed using multiple regression analysis. All exogenous constructs consisting of attitude $(\beta=0.570)$, perceived behavioral control $(\beta=0.244)$, and subjective norm $(\beta=0.082$ ) have positive and significant relationship with healthy eating intention. The model explained $56.7 \%$ of the variance in healthy eating intention with attitude being the most influential predictor. The findings confirm the applicability of TPB and provide indispensable insights in understanding the factors influencing the healthy eating intention among Malaysian adults. These findings can be used further to develop effective intervention programs in promoting healthier eating behaviors among the population.
\end{abstract}

Keywords: Healthy Eating, Intention, Theory of Planned Behavior

\section{Introduction}

There is rising awareness among Malaysians on the importance of healthy eating habits. Recent research reported that almost all Malaysians (99\%) are interested in practising a healthy diet and improving their food consumption habits (Food Industry Asia, 2019). This can be translated into the premise that Malaysians are getting more health conscious. The growing concern pertaining health issues has prompted the Malaysian government via the Ministry of Health $(\mathrm{MOH})$ to continuously promote various programs and campaigns on healthy eating and lifestyles. The main master plan executed was the continuation of the National Plan of Action for Nutrition of Malaysia (NPANM III, 2016 - 2025). Some of the programs highlighted in this framework related to promoting healthy eating and active living 
were the "Malaysian Dietary Guidelines", "Nutrition Surveillance on Pregnant Women and Infants", "Rehabilitation Programme for Malnourished Children", "Healthy Cafeteria", "Healthy Meal Provision during Meetings", and "Healthy Eating through Healthy Shopping". Despite the rising awareness and the various programs implemented to promote healthy eating, it seems to be unsuccessful in achieving the desired behaviors. This can be seen by the population's health statistics reported in the National Health and Morbidity Survey (NHMS 2019). The non-communicable diseases (NCDs) in this country are on the rise with 1.7 million Malaysians currently live with three major risk factors (diabetes, hypertension, and high cholesterol) and 3.4 million are living with two major risk factors. To make matters worse, cardiovascular diseases (CVDs) are the leading causes of death in Malaysia. In terms of prevalence of overweight and obesity, half of the total adult population in this country are overweight or obese. The ill-health condition is most likely due to the sedentary lifestyles and unhealthy eating practices among the population. One out of 4 Malaysian adults are not physically active and $95 \%$ of adults fail to meet the recommended daily consumptions of fruits and vegetables ( $\mathrm{MOH}, 2019)$.

The alarming statistics posit that most people may not have transformed their awareness into healthier eating behaviors. In response to this discrepancy between awareness and behavior, the most important concern is to develop some basis for understanding the behavior towards healthy eating. In the absence of actual behavioral measures, intention towards healthy eating would be the best instrument to predict the desired behaviors.

The Theory of Planned Behavior (TPB) undeniably is one of the best models in predicting the behavioral actions. The TPB is an expectancy-value model developed by Ajzen (1991). The theory proposes that people are more likely to engage in a specific behavior when they have the intention. In other words, the stronger the intention, the greater the likelihood to perform specific behavior. The intention is directly driven by three distinct constructs consisted of: the degree to which a person has a favorable or unfavorable evaluation of the behavior (attitude); the importance of others' perception whether to perform or not to perform the desired behavior and the willingness to comply to those referents (subjective norm); and the influence of an individual's perceived ease or difficulty in performing a specific intention or behavior (perceived behavioral control). In the TPB theoretical framework as shown in Figure 1 , perceived behavioral control (PBC) is proposed to have both direct and indirect effects toward behavior through intention.

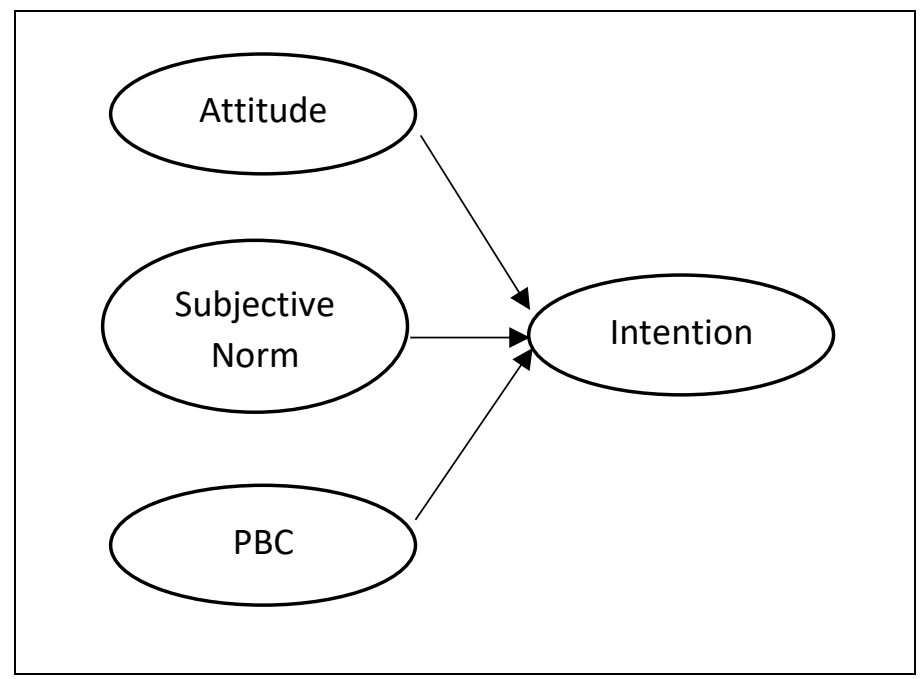

Figure 1: Theory of Planned Behavior (Ajzen, 1991) 
As one of the most influential theories in explaining the behavioral factors of individual's decisions or actions, the TPB is widely used in the literature. A plethora of studies have succeeded in applying the TPB to explain the consumers' knowledge or food choice behavior among different populations (Brouwer and Mosack, 2015; Liu, Lee and Hwang, 2021; Dowd and Burke, 2013; Mamun, Hayat and Zainol, 2020; Sanusi, 2020; Phang, Osman and Ginajil, 2020; McEachan et al., 2011; Aungatichart, Fukushige and Aryupong, 2020; Cheng et al., 2019). Of the three main constructs proposed to influence intention, some reviews of the TPB often resulted in attitude to be the strongest predictor as can be seen in Povey et al. (2000), Conner and Norman (2005), Grønhøj et al. (2012), and Mamun, Hayat and Zainol (2020). Interestingly some studies deduced that attitude is not statistically significant in explaining intention towards healthy eating (Cheng et al., 2019; Liu, Lee and Hwang, 2021). While a number of studies provide evidence that PBC is the best predictor of healthy eating intention, for example in Brouwer and Mosack (2015), Liu, Lee and Hwang (2021), and Cheng et al. (2019), some have found that PBC is the weakest predictor (McEachan et al., 2011). Subjective norm on the other hand has consistently reported as the least influential factor in predicting intention to eat healthily as cited in (Povey et al., 2000; Fila and Smith, 2006; Brouwer and Mosack, 2015).

The applicability of TPB in determining factors influencing healthy eating intention/behavior is undebatable and worth to be explored in Malaysian context. The severity of Malaysians' health condition urges an intense understanding of how far their intention towards healthy eating are shaped by attitudinal, normative and self-control factors as outlined in TPB model. Therefore, this study aims to identify the significant factors influencing Malaysians' healthy eating intention with the application of Theory of Planned Behavior (TPB). The findings of this study would provide indispensable insights in understanding the factors influencing the healthy eating intention among Malaysian population.

\section{Methodology}

\section{Conceptual Framework}

In this study, a conceptual framework based on the TPB developed by Ajzen (1988) was applied to explain the relationships between three exogenous constructs (attitude, subjective norm, and PBC) and the endogenous construct (healthy eating intention). The three exogenous constructs are hypothesized to have positive and significantly related to the healthy eating intention.

\section{Sample Design}

A total of 1,719 adults aged 18 years and above participated in this study. The target respondents were approached at major shopping malls in 14 capital states and federal territory all over the country. Systematic random sampling was used to select the potential respondents. The selected respondents were asked to complete the questionnaires assisted by the enumerators.

\section{Survey Instrument}

The questionnaire was divided into two main sections. The first section consisted of demographic questions including gender, ethnicity, age, marital status, education level, and personal income. The second section comprised of questions/items derived from previous studies to measure the attitudinal, normative, self-control and intentional factors toward healthy eating (Povey et al., 2000; Conner and Norman, 2005; Fila and Smith, 2006). The 
number of questions for each construct ranging from 3 to 13 items in which attitude has 7 items, subjective norm (6 items), PBC ( 3 items), and intention (13 items). All items were measured using the 7-point Likert scale, ranging from 1 = "strongly disagree" to 7 = "strongly agree".

\section{Data Analyses}

The analyses conducted comprised of descriptive, reliability and multiple linear regression. All analyses were performed using SPSS software (version 23.0). The descriptive analysis was carried out to summarize the demographic profiles of respondents, and also the mean and standard deviation for each item in this study. The reliability analysis was performed to test the internal consistency which refers to the degree to which the items measuring the same underlying construct. The most common indicator of internal consistency is the Cronbach's $\alpha$ coefficient with the ideal value of 0.70 and above indicating sufficient internal reliability (Pallant, 2016). Finally, the multiple regression analysis was conducted to determine the relationship between the three exogeneous constructs and the endogenous construct.

\section{Results}

\section{Demographic Characteristics}

Table 1 shows the distribution of main demographic characteristics of this study. More than half of the respondents were female (58.7\%), young adults below 30 (53.4\%), and married (50.1\%). In parallel with the population's distribution of ethnicity, majority were Malays $(62.5 \%)$, followed by Chinese (21.6\%), Indians (7.6\%), and other ethnics (8.2\%). In terms of education level, majority of the respondents were educated up to tertiary level $(69.1 \%)$. Regarding the data collection on income, approximately $90.0 \%$ of the respondents were willing to provide data on their income. Slightly over $64 \%$ were classified as moderate-income earners (RM1500 - RM4999), 22.7\% were low-income earners (below RM1500) while the remaining $12.9 \%$ belonged to high-income bracket (RM5000 and above). 
Table 1: Demographic characteristics

\begin{tabular}{|c|c|c|c|c|c|}
\hline & $\mathrm{N}$ & $\begin{array}{l}\text { Valid } \\
\text { percentage }\end{array}$ & & $\mathrm{N}$ & $\begin{array}{l}\text { Valid } \\
\text { percentage }\end{array}$ \\
\hline Gender & & & Marital status & & \\
\hline Male & 710 & 41.3 & Married & 858 & 50.1 \\
\hline Female & 1009 & 58.7 & Single & 802 & 46.8 \\
\hline \multirow[t]{2}{*}{ Total } & 1719 & 100.0 & Others & 52 & 3.1 \\
\hline & & & Total & 1719 & 100.0 \\
\hline \multicolumn{6}{|l|}{ Ethnicity } \\
\hline Malay & 1075 & 62.5 & Education level & & \\
\hline Chinese & 372 & 21.6 & Secondary school & 532 & 30.9 \\
\hline Indian & 131 & 7.6 & $\begin{array}{ll}\text { Diploma } & \text { or } \\
\text { equivalent } & \end{array}$ & 466 & 27.1 \\
\hline Others & 141 & 8.2 & Bachelor's degree & 529 & 30.8 \\
\hline \multirow[t]{2}{*}{ Total } & 1719 & 100.0 & Postgraduate & 192 & 11.2 \\
\hline & & & Total & 1719 & 100.0 \\
\hline \multicolumn{6}{|l|}{$\underline{\text { Age }}$} \\
\hline Below 21 & 150 & 8.7 & $\frac{\text { Personal income }}{(\mathrm{RM})}$ & & \\
\hline $21-30$ & 768 & 44.7 & Below 1500 & 352 & 22.7 \\
\hline $31-40$ & 436 & 25.4 & $1500-2999$ & 568 & 36.7 \\
\hline $41-50$ & 217 & 12.6 & $3000-4999$ & 429 & 27.7 \\
\hline Above 50 & 148 & 8.6 & 5000 and above & 199 & 12.9 \\
\hline Total & 1719 & 100.0 & Total & 1548 & 100.0 \\
\hline
\end{tabular}

Reliability Analysis

In this study, Cronbach's $\alpha$ coefficient was used to measure the internal consistency of the scale. As presented in Table 2, all constructs have demonstrated good to excellent internal reliability with the value of Cronbach's $\alpha$ ranging from 0.81 to 0.95 . The mean for each item showed attitude has the highest level of agreement on the items' statements while subjective norm has the lowest mean scores. 
Table 2: Descriptive statistics of the constructs and Cronbach's $\alpha$

\begin{tabular}{|c|c|c|}
\hline Constructs & Items & Mean/s.d. \\
\hline \multirow{7}{*}{$\begin{array}{l}\text { Attitude } \\
\text { (Cronbach's } \alpha= \\
0.92 \text { ) }\end{array}$} & To me, healthy eating is very important for my overall health. & $5.94 \pm 1.09$ \\
\hline & $\begin{array}{l}\text { I believe eating healthy food is helpful in preventing serious } \\
\text { diseases such as diabetes, heart disease, cancer, and obesity. }\end{array}$ & $6.05 \pm 1.04$ \\
\hline & I feel good about myself when I eat healthy food. & $5.84 \pm 1.12$ \\
\hline & To me, healthy food helps me to keep my ideal weight. & $5.81 \pm 1.15$ \\
\hline & I believe it is important to me to eat healthy foods every day. & $6.02 \pm 1.05$ \\
\hline & $\begin{array}{l}\text { In my opinion, eating a healthy diet improves my overall } \\
\text { physical health. }\end{array}$ & $5.97 \pm 1.04$ \\
\hline & In my opinion, eating healthy foods improves the way I look. & $5.69 \pm 1.16$ \\
\hline \multirow{6}{*}{$\begin{array}{l}\text { Subjective } \text { norm } \\
\text { (Cronbach's } \alpha= \\
0.88 \text { ) }\end{array}$} & $\begin{array}{l}\text { Most people who are important to me think I should eat a } \\
\text { healthy diet. }\end{array}$ & $5.23 \pm 1.39$ \\
\hline & My friends keep telling me to watch carefully of what I eat. & $4.69 \pm 1.46$ \\
\hline & $\begin{array}{l}\text { My doctor/health professional asks me to practice a healthy } \\
\text { diet. }\end{array}$ & $4.79 \pm 1.61$ \\
\hline & $\begin{array}{l}\text { My family keep telling me to eat healthily to avoid serious } \\
\text { conditions such as heart disease, diabetes, cancer, and } \\
\text { obesity. }\end{array}$ & $5.21 \pm 1.45$ \\
\hline & $\begin{array}{l}\text { My colleagues influence me to change my diet into a } \\
\text { healthier one. }\end{array}$ & $4.48 \pm 1.58$ \\
\hline & $\begin{array}{l}\text { Since someone in my family/friend involve in health-care } \\
\text { related occupations, they advise me to watch carefully of my } \\
\text { diet. }\end{array}$ & $4.59 \pm 1.64$ \\
\hline \multirow{3}{*}{$\begin{array}{l}\text { PBC (Cronbach's } \alpha \\
=0.81)\end{array}$} & I have the ability to opt for healthy food when I eat out. & $5.00 \pm 1.36$ \\
\hline & $\begin{array}{l}\text { I feel that I can keep the amount of fat, sugar, and salt at a } \\
\text { healthy level if I want to. }\end{array}$ & $5.39 \pm 1.19$ \\
\hline & $\begin{array}{l}\text { I am capable of eating a variety of foods within their } \\
\text { recommended intake. }\end{array}$ & $5.24 \pm 1.24$ \\
\hline \multirow{11}{*}{$\begin{array}{l}\text { Intention } \\
\text { (Cronbach's } \alpha= \\
0.95)\end{array}$} & I intend to eat a healthy diet because it is good for my health. & $5.74 \pm 1.19$ \\
\hline & I want to eat plenty of fresh fruits and vegetables. & $5.82 \pm 1.13$ \\
\hline & $\begin{array}{l}\text { I will try my best to keep the amount of fat, sugar, and salt I } \\
\text { eat at a healthy level. }\end{array}$ & $5.70 \pm 1.16$ \\
\hline & I will reduce the intake of unhealthy snack and titbits. & $5.64 \pm 1.22$ \\
\hline & I intend to carefully watch what I eat. & $5.67 \pm 1.15$ \\
\hline & I plan to drink at least eight glasses of water every day. & $5.82 \pm 1.15$ \\
\hline & I will try to limit the intake of fast food. & $5.70 \pm 1.16$ \\
\hline & I will try to limit the intake of red meat. & $5.52 \pm 1.23$ \\
\hline & I will cook healthier food in the future. & $5.71 \pm 1.16$ \\
\hline & $\begin{array}{l}\text { I will read nutrition information and food labels before I } \\
\text { purchase any food. }\end{array}$ & $5.52 \pm 1.29$ \\
\hline & I will try my best to avoid eating foods that contain additives. & $5.60 \pm 1.21$ \\
\hline
\end{tabular}




\begin{tabular}{|l|l|l|}
\hline & $\begin{array}{l}\text { I intend to reduce the intake of processed and convenience } \\
\text { foods in my diet. }\end{array}$ & $5.58 \pm 1.18$ \\
\cline { 2 - 3 } & I plan to follow a healthy and balanced diet. & $5.74 \pm 1.16$ \\
\hline
\end{tabular}

Regression Analysis

Table 3 shows the results of multiple linear regression indicating a fit and significant model $(F$ $=741.786 ; p<0.000)$. All three exogenous constructs consisting of attitude, subjective norm and PBC are positively significant predictors at 0.01 level of significance. The adjusted $R^{2}$ value suggesting that $56.7 \%$ of the variance in healthy eating was explained by the three exogenous constructs. Looking closely at each individual exogenous construct, attitude with $\beta=0.570$ appeared to be the most influential predictor of healthy eating intention. Subjective norm ( $\beta$ $=0.082$ ) on the other hand was the least useful predictor of intention.

Table 3: Results of multiple linear regression

\begin{tabular}{llll}
\hline & $\beta$ & SE & Sig. \\
\hline Constant & 0.632 & 0.109 & 0.000 \\
Attitude & 0.570 & 0.019 & 0.000 \\
Subjective norm & 0.082 & 0.014 & 0.000 \\
PBC & 0.244 & 0.017 & 0.000 \\
\hline$F=741.786$ & & \multicolumn{2}{l}{ Adjusted $R^{2}=0.567$} \\
\hline
\end{tabular}

\section{Discussion and Conclusion}

Similar to other modern populations and the country's tremendous efforts toward achieving a developed nation, Malaysians are facing threatening health risks inevitably associated with the transition in lifestyles. Most Malaysians are practising sedentary lifestyle including lack of physical exercise and increased screen-based activities. In addition, the unhealthy eating habits lead to the increased prevalence of chronic and NCD diseases in the population. A welldocumented theory such as the TPB would possibly be a perfect model in explaining the behavioral intention towards healthy eating. The results of this study found positive and significant relationships between all exogenous constructs and the healthy eating intention. This is in line with most of the previous studies determining the model fit of TPB in healthy eating context (Povey et al., 2000: Conner and Norman, 2005; Brouwer and Mosack, 2015). As reported in the descriptive findings, respondents had highly positive attitudes and intention on performing healthy eating behavior. This therefore indicates that the Malaysian adults are willing to change their eating habits into healthier ones. The results further suggested that attitude was the most influential predictor of intention. This is consistent with previous studies by Povey et al. (2000), Conner and Norman (2005), Grønhøj et al. (2012), and Mamun, Hayat and Zainol (2020). Therefore, the designed promotion on healthy eating should focus to a great degree on strengthening the positive attitudinal factors. Most people recognized the importance of healthy eating. They believe practising healthy eating behaviors is helpful in preventing chronic diseases including diabetes, cancer, and obesity. Furthermore, eating healthily is believed to improve overall physical health, keep an ideal weight for better appearance, and make one feels good. In this regard, the promotion on healthy eating should emphasis on the role of healthy eating in combating the NCDs as well as a tool to improve the physical appearance and self-satisfaction.

Other than the attributes of attitude, the PBC also plays a significant and important role in behavioral intention. Most people may have high self-control to adhere to healthy behaviors 
such as to opt for healthy food when dining out, keep the amount of fat, sugar, and salt at a healthy level, and eat variety of foods within the recommended intake. While most people in general are aware of their unhealthy food consumption, instead they find it is hard to resist delicious but often unhealthy food such as roti canai, nasi lemak, and teh tarik. As such, the promotion on healthy eating should consider on strengthening the people's self-control in achieving the desired behaviors.

The role of subjective norm which refers to complying to other people's expectation, although still significant in influencing intention to eat healthily, appeared to be not as influential as attitude and PBC. This is supported by other studies that concluded subjective norm as the least influential predictor of intention specifically in healthy eating intention (Povey et al., 2000; Fila and Smith, 2006; Brouwer and Mosack, 2015). In this study, most of the mean items in subjective norm showed relatively low scores than other constructs. Therefore, the finding suggests that in adulthood, other people's expectation may not serve as an important role in influencing one's intention towards healthy eating. This may explain why the extensive healthy eating campaigns seem to fail in meeting the targeted behavior among Malaysian adults.

The findings of this study would provide theoretical and practical contributions to the body of knowledge in understanding the factors influencing the healthy eating intention. In theoretical contribution, the findings of this study add to the literature on the application of the TPB in the domain of healthy eating. Regarding the practical contribution, the study reflects the needs for the food marketers and government to thoroughly understand the population's intention towards healthy eating. The food marketers should provide healthy food options as Malaysians are getting more health conscious. In terms of designing more effective intervention programs on promoting healthier eating behavior, the government via the $\mathrm{MOH}$ should focus on transforming internal factors including changing people's attitudes into more positive as well as enhancing their self-control towards healthy eating.

In conclusion, this study provides better insights in understanding the factors influencing adults' healthy eating intention. However, there is one vital area needs to be explored for future research. As the results indicated that the variance of healthy eating intention explained by the three main constructs was less than $60 \%$, further study should consider adding more relevant variables to enhance the prediction of healthy eating intention. Other factors beyond the TPB components may be able to explain the gap between the high intention and the poor actual behaviors in healthy eating.

\section{References}

Ajzen, I. (1991). The Theory of Planned Behavior. Organizational Behavior and Human Decision Processes, 50, 179-211.

Aungatichart, N., Fukushige, A., Aryupong, M. (2020). Mediating Role of Consumer Identity between Factors Influencing Purchase Intention and Actual Behavior in Organic Food Consumption in Thailand. Pakistan Journal of Commerce and Social Sciences, 14(2), 424449.

Brouwer, A. M., Mosack, K. E. (2015). Expanding the Theory of Planned Behavior to Predict Healthy Eating Behaviors. Exploring a Healthy Eater Identity. Nutrition and Food Science, 45(1), 39-53.

Cheng, O. Y., Yam, C. L. Y., Cheung, N. S., Lee, P. L. P., Ngai, M. C., Lin, C. Y. (2019). Extended Theory of Planned Behavior on Eating and Physical Activity. Am J Health Behav, 43(3), 569-581. 
Conner, M., Norman, P. (2005). Predicting Health Behavior. Safety Science, 24, 408.

Dowd, K., Burke, K. J. (2013). The Influence of Ethical Values and Food Choice Motivations on Intentions to Purchase Sustainably Sourced Foods. Appetite, 69, 137-144.

Grønhøj, A., Bech-Larsen, T., Chan, K., Tsang, L. (2012). Using Theory of Planned Behavior to Predict Healthy Eating among Danish Adolescents. Health Educ, 113(1), 4-17.

Fila, S. A., Smith, C. (2006). Applying the Theory of Planned Behavior to Healthy Eating Behaviors in Urban Native American Youth. International Journal of Behavioral Nutrition and Physical Activity, 3, 1-10.

Food Industry Asia. (2019). Majority of Malaysian Consumers Want Healthy Foods but Cost is a Deterrent. IGD Articles. https://www.igd.com/articles/article-viewer/t/majority-ofmalaysian-consumers-want-healthy-foods-but-cost-is-a-deterrent/i/21620

Liu, D., Lee, S., Hwang, J. (2021). Factors Related to the Intention of Healthy Eating Behaviors Based on the Theory of Planned Behavior: Focused on Adults Residing in Beijing, China. J Nutr Health, 54(1), 67-75.

Mamun, A. A., Hayat, N., Zainol, N. R. (2020). Healthy Eating Determinants: A Study among Malaysian Young Adults. Foods, 9(974), 1-18.

McEachan, R. R. C., Conner, M., Taylor, N. J., Lawton, R. J. (2011). Prospective Prediction of Health-related Behaviors with the Theory of Planned Behavior: A Meta-analysis. Health Psychology Review, 5(2), 97-144.

Ministry of Health Malaysia. (2019). National Health and Morbidity Survey 2019. Noncommunicable Diseases, Healthcare Demand, and Health Literacy: Key Findings. Institute for Public Health.

http://www.iku.gov.my/images/IKU/Document/REPORT/NHMS2019/Infographic_ Booklet_NHMS_2019-English.pdf

Pallant, J. (2016). SPSS Survival Manual: A Step By Step Guide to Data Analysis Using SPSS Program (6th ed.). London, UK: McGraw-Hill Education.

Phang, I @ G., Osman, Z., Ginajil, J. E. (2020). Determinants of Young Malaysian Adults' Fast Food Purchasing Intention. Malaysian Journal of Business and Economics, 7(1), 1-15.

Povey, R., Conner, M., Sparks, P., James, R., Shepherd, R. (2000). The Theory of Planned Behavior and Healthy Eating: Examining Additive and Moderating Effects of Social Influence Variables. Psychology and Health, 14, 991-1006.

Sanusi, G. A. (2020). Factors Influencing the Intention to Use Malaysian Dietary Guidelines among University Students. International Journal of Economics, Management and Accounting, 28(2), 517-543. 